\title{
The Performance Tested of Multichannel Data Acquisition System In Measurement of Soil Moisture
}

\author{
[R. Ekawita ${ }^{1}$, Z. B. Caniago' ${ }^{1}$ Supanjani² $^{2}$, A. D. Nusantara ${ }^{2}$, M. S. Abidin 3 \& Y.I. Intara $\left.{ }^{4}\right]$
}

\begin{abstract}
One of the soil conditions that affect the development of a plant and crop production is the soil moisture. Therefore, it is necessary to monitor this property with multi points and real time of observation around the plant environment. In this research, it had been designed and tested a multichannel soil moisture measurement system with the wireless communication system. The system consists of transmitter and receiver blocks using soil moisture sensors as a soil moisture detector and microcontroller media in both blocks as the overall control of the measurement system. The measured result data is observed directly through the PC display. Laboratory scale testing is done as calibration process of the output voltage from sensor to soil moisture. The soil moisture $14.45 \% ; 19.92 \%$ and $26.73 \%$ comparable to 4.71 volt; 4.13 volt and 3.06 volt output voltage respectively. While the resistance values of each humidity were equal to $170.87 \mathrm{k} \Omega$; $49.49 \mathrm{k} \Omega$ and $16.36 \mathrm{k} \Omega$. The whole system test is done in the field (oil palm plantation ) with the result obtained that the content of water contented which is pretty much found at the top near the rooting of fibers and the bottom (subsoil).
\end{abstract}

Keywords-Soil Moisture, Transmitter, Receiver, Multichannel, Microcontroller.

\section{Introduction}

In agriculture and biological science, soil moisture is an important thing to plant growth and crops production levels [3-5]. Regularly observation and management of soil moisture are essential to prevent drought in plants although this is also influenced by the season and the size and number of the plant's canopy itself.

Measurement of both the soil and materials properties can be done directly and indirectly. The direct method utilizes a transducer/sensor that is direct contact with the object to be measured as well as the LVDT sensor [6], strain gage [1], probe [7] etc. While the indirect method, the sensor is not in contact with the object, for example, image processing technique [8,9], frequency [10,11], satellite[7] and computation technique $[5,10]$.

\section{R. EkawitaI, Z. B. Caniago}

Faculty of Mathematics and Natural Sciences, The University of Bengkulu, Jl. WR. Supratman Kandang Limun Bengkulu, 38371

Indonesia,

Supanjani $^{2}$, A. D. Nusantara

Faculty of Agriculture, The University of Bengkulu, Jl. WR. Supratman Kandang Limun Bengkulu, 38371

Indonesia,

M. S. Abidin

Mandala Waluya School of Health Science, Southeast Sulawesi Indonesia,

Y.I. Intara ${ }^{4}$

Faculty of Agriculture, The Universitas of Mulawarman, J1. Paser Balengkong Kampus Gunung Kelua Samarinda,

Indonesia
Various developments of measurement techniques to obtain better results have also been made, not only on the methods but also on the equipment that accompanies the measurement like a type of microcontroller, communication data method etc [12-13]. Currently, the real time [14] and continuously of measurement system will provide more value than existing tools. In addition, multiple points of measurement simultaneously to obtain data or information at the same time can yield much better and more significant results [15] than a single measurement point that is only considered to represent a condition.

This paper will describe a data acquisition system for measuring soil moisture that can measure many observation points continuously. It is therefore expected to result in more precise soil moisture measurements and to provide an overview of the distribution of moisture content in the soil. Development of communication system is also done by utilizing wireless technology.

\section{Acquisition System Description}

Multi point acquisition system was made in order to monitor multi points simultaneously and continuously. This system consisted of hardware and software part. The hardware part included transmitter system and receiver system. While the software was part of the receiver system in the form of monitoring serial of the microcontroller used. The measurement data will be displayed on the software provided on the computer. In general, the block diagram of the acquisition system can be seen in Figure 1.

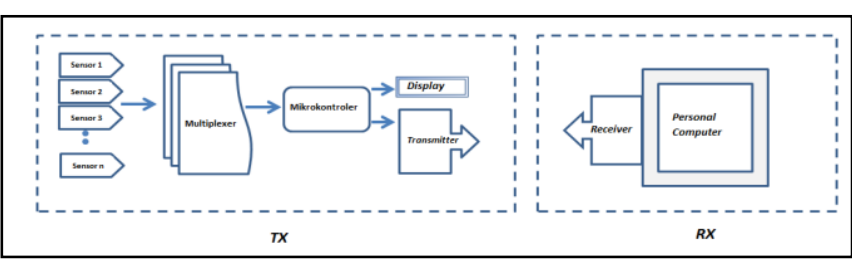

Figure 1. Block diagram of data acquisition system

Electrical signals from each sensor will go into the multiplexer and send to the microcontroller in turn. Analog signals that is transmitted by the mux will be digitized by the ADC (analog to digital converter) before being further processed by the microcontroller. The output from microcontroller will be viewed directly on the display on the transmitter system and it sent to the receiver system for display on the PC (personal computer). 


\section{Transmitter}

In Figure 1, it is stated that transmitter part is a whole circuit system starting from the sensor until the data is ready to be transmitted. The work phase of this section starts with reading the data, processing and transmitting to the receiver. The method of transmitting data from transmitter to receiver is by wireless.

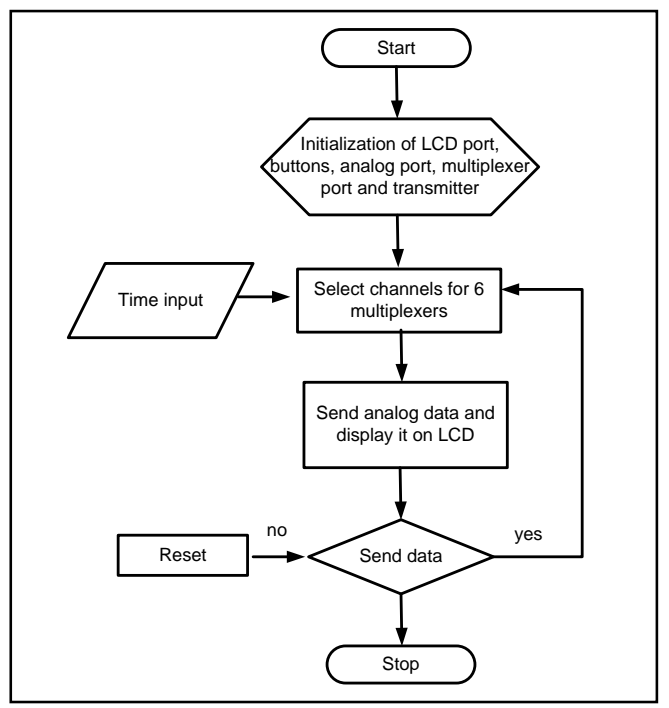

Figure 2. Transmitter's flowchart

The circuit for 48 input sensor is connected to a multiplexer in order to read data sequentially. The sensor read the quantity to be measured in the form of electrical response. The sensor used to detect soil moisture level was soil moisture sensor FC-28. The data read from sensor 1 to sensor 48 was sequenced first by the multiplexer (mux) before processed to the next stage.

The analog signal generated from the mux was sent to the converter (ADC). ADC uses a 5 volt of reference voltage. A 10-bit ADC meaning it has the ability to detect 1,024 (210) discrete analog levels in the 5 volt voltage range. 10 bit $\mathrm{ADC}$ converted the analog signal into the digital signal to be processed by the microcontroller. Data resulted from microcontroller was sent one by one to the receiver $(\mathrm{Rx})$. The flowchart in Figure 2 shows a complete process of reading and processing by the microcontroller in transmitter part.

At the first time when the transmitter switch was turned on, the microcontroller would initialize the ports used, starting from the port used for the LCD, the port for setting buttons, the port for analog input, for the multiplexer and for the transmitter. The initialization was done in preparation for the system in conducting the measurement process. Next steps, channel selection for multiplexer was done. This research used 6 multiplexers that read the output from 48 moisture sensors. Each mux had 8 channels where reading was arranged interchangeably by the microcontroller. The reading stopped for a while based on the input delay which given after all the channels of each mux were read. After all the channels of each mux are read, then the reading will stop some time based on the input delay time given from the buttons. The data of each channel of each mux was displayed alternately on the LCD screen. The $16 \times 2$ LCD on the transmitter system is a temporary measurement viewer of all sensors before being sent to the receiver. The data will appear on LCD sequentially from 1-48 sensors. The measurement results on the LCD will continue to repeat according to the settings of the time button from the outside and or the reset button.

Each data was also transmitted to the receiver and appeared on PC. The process of transmitting data would not be done if there were a reset command of the reset button. If there were no such command, then data would be transmitted continuously until reached 48 sensor data and finished.

\section{Receiver}

The receiver used in this research was a combination of hardware (electronic) and software (serial monitoring software). When this part was activated, the receiver gave a ready indicator to receive data from the transmitter. The flow diagram of data receiving process by microcontroller contained in the receiver is shown in Figure 3.

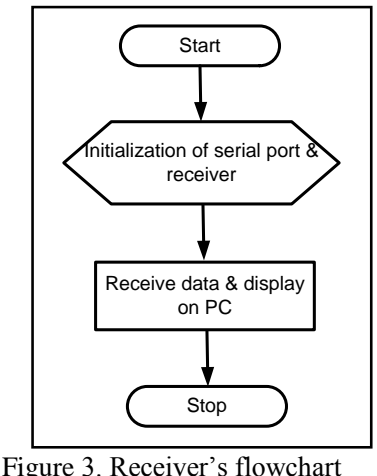

Data receiving process in the receiver was started by connecting receiver to the computer where the software to display measurement data on PC was active. Data reception stage began with the initialization of the port by the microcontroller that started from the serial port used to communicate and receiver port. Then the system continuously displayed data from transmitter until the finish on serial monitor software.

\section{v. Soil Moisture Sensor}

Soil moisture sensor FC-28 is moisture sensor which able to detect soil moisture with the principle of resistance changes. Higher soil moisture gives smaller resistance while smaller soil moisture gives higher resistance value [16]. So resistance and soil moisture have an inversely relationship. This response was analyzed to determine soil moisture level in certain areas.

\section{Result and Discussion}

Works of functional blocks were tested according to their respective functions then followed with integration process between hardware and software. When integration process completed, all system was tested together and then validation was done.

The circuit was tested on multichannel channels system in order to check the performance and whether it already met the criteria, plan, and expectation. If those had not been achieved or still some obstacles and some lacks, some improvement could be done. 


\section{A. Calibration}

Calibration was done to find out the level of linearity of sensor output to change into soil moisture detected. Sensors used in this system produce a response in resistance to changes in surrounding humidity environment. It has been performed several times the calibration processed for different soil moisture conditions.

Calibration preparation of soil moisture was done by preparing the soil, air dried and milled using wood then filtered with mesh size $2 \mathrm{~mm}$. The soil used in this research was taken from the area around The University of Benngkulu.

The prepared soil was cleaned clearly from dirt and then put into a cylindrical plastic container. Each soil sample was weighed using digital scale "Ohaus CL481T series" and divided into 3 parts where each sample had 248 grams weight. Certain moisture was given into soil sample in each container. The dry and wet soil mass are weighed to determine soil moisture of samples. Using (1) and both of these soil masses, soil moisture can be identified. For instance, Ws is the mass of wet soil, Ds is the mass of dry soil, Mw is the water mass and SM is the soil moisture in each sample tested.

$$
\begin{gathered}
M_{w}=W_{s}-D_{s} \\
S M=\left(M_{w} / D_{g}\right) \times 100 \%
\end{gathered}
$$

After the soil for moisture test is prepared, then for each test sample is plugged in the soil moisture sensor (Figure 4). This is done to know the conversion of electric signal from sensor (Soil Moisture Sensor FC-28) to soil moisture. This data retrieval process is done at one time with the position of 6 sensors in a 6 plastic containers of soil with a certain water content. The reader system is set to retrieve the soil moisture data on to each sensor in sequence after all the sensors are reading then the system will standby for 1 minute and then reread again in sequence again. This measurement process is done repeatedly.

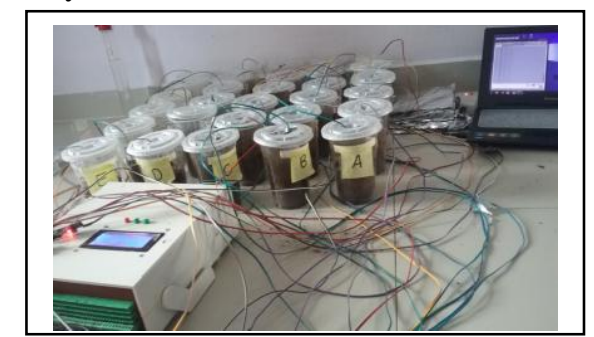

Figure 4. Device and data testing process in laboratory

The output of measurements that appear on the acquisition system is a voltage value (Vo). This voltage will be further processed by using the principle of the voltage divider circuit (2) to obtain the soil resistance value $(\mathrm{Rx})$ at the time of measurement.

$$
V_{0}=\frac{R_{x}}{\left\{R_{i}+R_{x}\right)} \cdot V_{i}
$$

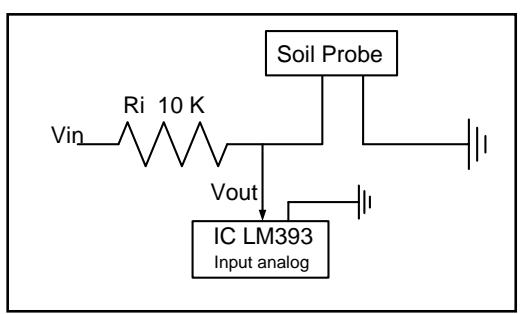

Figure 5. Schematic of soil moisture

Figure 5 is a schematic representation of the voltage divider circuit of soil moisture sensor. The output voltage of measurements read by the acquisition system is fed into the equation 2 so that the resistance relationship is inversely proportional to the soil moisture.

\section{B. Sensor Characteristic Result}

The character of the sensor was done by simultaneous measurement testing using soil moisture sensor FC-28 where one sensor was located in each plastic container containing certain moisture content. The measurement was repeated 12 times of each sensor for different soil moisture. From here, the character and basic performance of soil moisture sensor FC-28 can be defined.

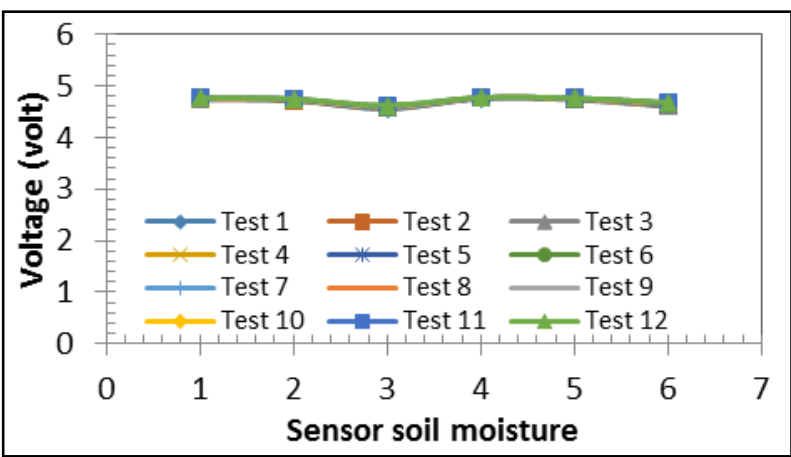

Figure 8. Testing graph of soil moisture sensor FC-28 on soil moisture $14.45 \%$ sample

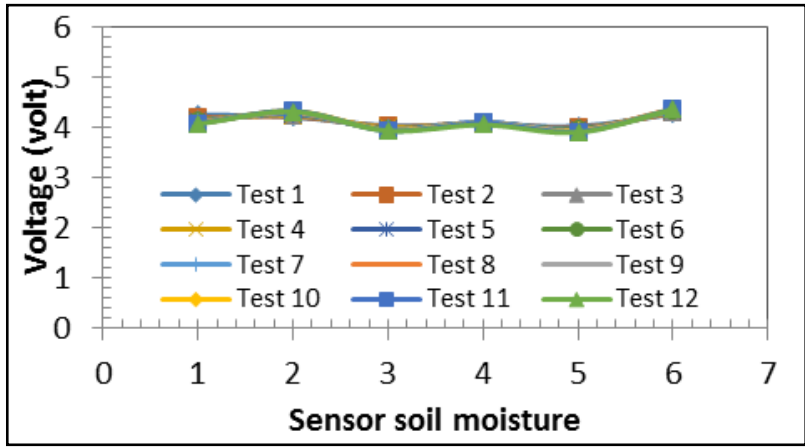

Figure 9. Testing graph of soil moisture sensor FC-28 on soil moisture $19.92 \%$ sample

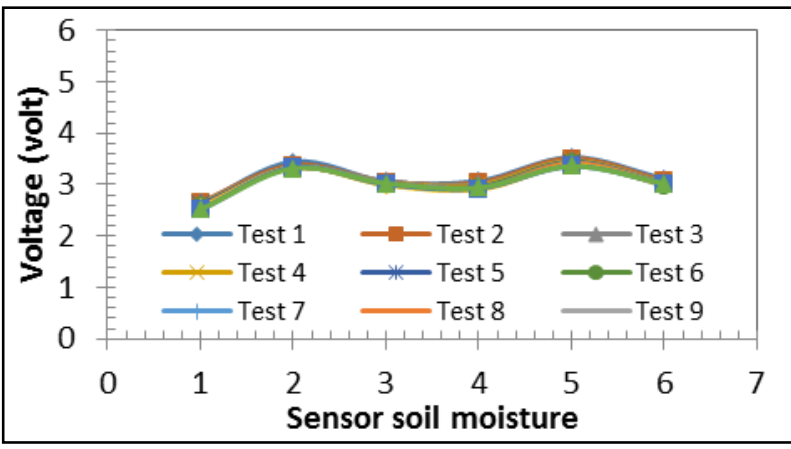

Figure10. Testing graph of soil moisture sensor FC-28 on soil moisture $26,73 \%$ sample

Sensors produce different output voltage responses from each different moisture level. Repeated measurements show results that are not much different (constant). Figure 8, 9, 10 are the result of sensor characteristic test with different soil moisture level from humidity $14.45 \%$ to $26.73 \%$ and the 
Proc. of the Eighth International Conference On Advances in Applied Science and Environmental Engineering - ASEE 2018 Copyright (C) Institute of Research Engineers and Doctors. All rights reserved.

ISBN: 978-1-63248-143-6 doi: 10.15224/ 978-1-63248-143-6-05

measurement results are stable enough. For the above soil moisture values are obtained output voltage ranges 4.71 volt; 4.13 volt and 3.06 volt.

The output voltage of measurement is fed into the equation 2 so that resulting in a resistance relationship with soil moisture such as Figure 11. The resistance has an upside-down relationship following the trend line exponent with soil moisture.

Overall, sensor showed good performance. The higher the soil moisture then the measured voltage will be lower. Each sensor has a good repeatability measurement value. The system successfully transmitted measurement result by the wireless method with indoor coverage with maximum wall distance was $4 \mathrm{~m}$.

\section{Testing of system in field}

First stage testing of the multichannel device was conducted at PT. Bio Nusantara in Afdeling 3 area for palm oil plant at age of 7 years. The sensor was located in a soil hole below the palm oil tree.

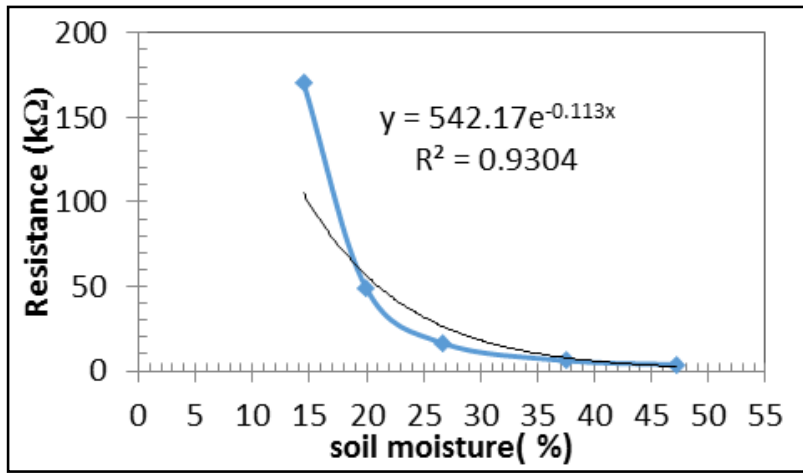

Figure 11. Correlation of soil moisture and soil resistance

The scheme for placing the sensors and the whole system in the oil palm plants as shown in Figure 12.b. The multichannel system uses a sensor matrix with a $7 \times 7$ pattern
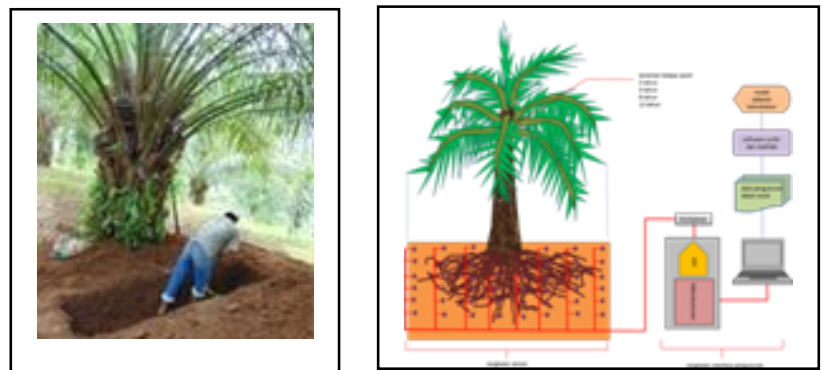

Figure 12. Soil hole for a multichannel system tested and measurement scheme

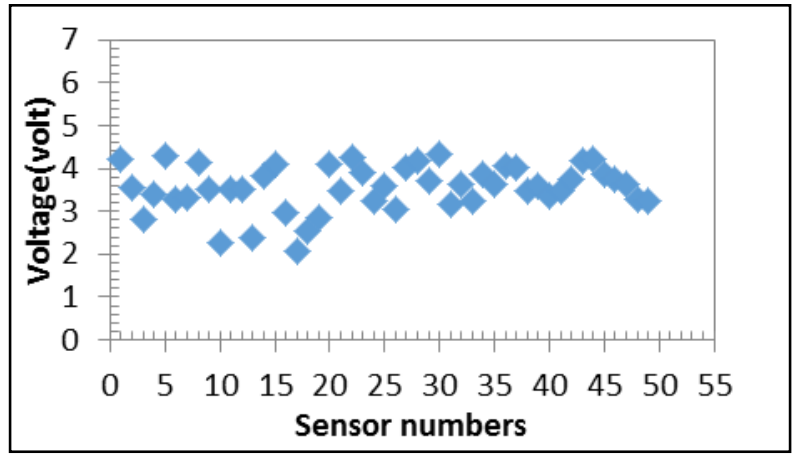

Figure 13. Measurement result of multichannel device for soil moisture tested

Soil hole was made a day before application testing with a size of 1,2 $\times 0,5 \times 2 \mathrm{~m}$ (Figure 12.a). of the root system and the observation hole. Measurements by the multichannel system were performed repeatedly for 180 minutes. The result is a voltage value of each sensor then the value is averaged to obtain a graph like a Figure 13.

The data was processed to distribution contour of soil moisture under palm oil tree using Surfer 7 software. This graph describes soil moisture distribution, which available under palm oil tree. Based on the result of distribution pattern (Figure 14), it can be seen that the distribution of moisture content is quite high at the top near the rooting of fibers and the bottom (subsoil). Water movement is critical in determining the water distribution in the soil. Rapid water movement is easier to move water; thus, water is evenly distributed in the soil solum. This condition supports soil biochemical process/reaction, which then influences soil nutrient. Besides influenced by moisture content, nutrient content in the root zone is also influenced by water movement, which carries nutrient. The transient state of the unsaturated flow occurs when the value of the flux, hydraulic conductivity, and moisture at each point along the flow and at any time is varies.
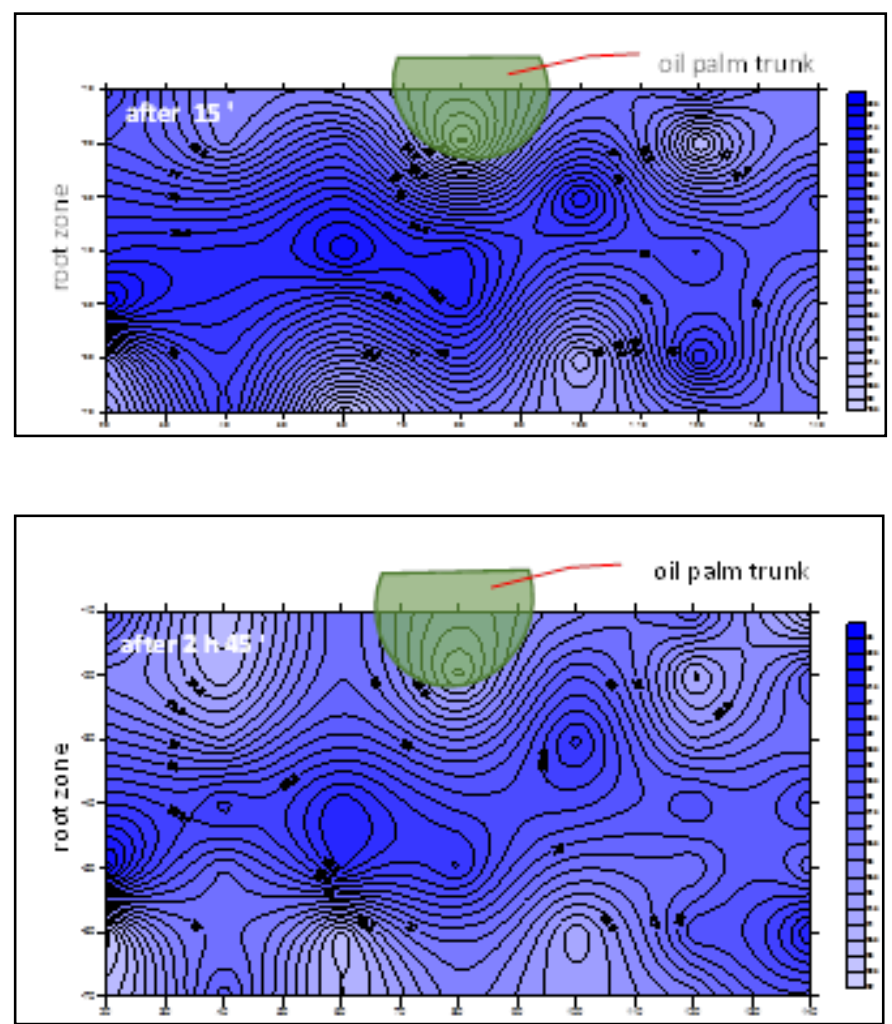

Figure 14. Distribution contour of soil moisture as the result of multichannel system measurement

\section{Conclusion}

Multichannel soils moisture measurement systems have been assembled and tested both on a laboratory scale and on a field scale. Laboratory scale tests were performed with soil moisture from $14.45 \%, 19.92 \%$, and $26.73 \%$. The soil resistance obtained with soil moisture was $170.87 \mathrm{k} \Omega ; 49.49$ $\mathrm{k} \Omega$ and $16.36 \mathrm{k} \Omega$. While from the field tested, it was obtained in the form of contours of water distribution of the 
soil in root palm. The content of water content is quite abundant at the top near the root of fibers and the bottom (subsoil).

\section{Acknowledgment}

This work was funded by the BPDPKS (Badan Pengelola Dana Perkebunan Kelapa Sawit) and supported by PT. Bio Nusantara.

\section{References}

[1] Ekawita, R., Khairurrijal, Munir, M. M., Suprijadi, \& Nawir, H, "A comprehensive characterization of a linear deformation sensor for applications in triaxial compression tests," Proc. of International Conference on Computer, Control, Informatics and Its Applications, Jakarta, Indonesia, pp. 191-194, 2013.

[2] Sugianto, N., Farid, M. \& Suryanto, M, "Local geology condition of bengkulu city based on seismic vulnerability index," ARPN Journal of Engineering \& Applied Science, vol. 11(7), pp. 4797-4803, 2016.

[3] Shittu, K. A., Oyedele, D. J. \& Babatunde, K. M, "The effects of moisture content at tillage on soil strength in maize production," Egyptian Journal of Basic and Applied Sciences, vol. 4, pp. 139-142, 2017

[4] Kourgialas, N., Doupis, G., Papafilippaki, A., Psarras, G. \& Koubouris, G, "Seasonal variation of soil moisture in irrigated olive trees," Procedia Engineering, vol. 162,pp. 471- 475, 2016.

[5] Carrão, H., Russo, S., Sepulcre-Canto, G. \& Barbosa, P, “An empirical standardized soil moisture index for agricultural drought assessment from remotely sensed data," International Journal of Applied Earth Observation and Geoinformation, vol. 48, pp. 74-84, 2016.

[6] Vu, X. H., Malecot, Y. \& Daudeville, "Strain measurements on porous concrete samples for triaxial compression and extension tests under very high confinement," Journal Strain Analysis, vol. 44, pp. 633- 657, 2009

[7] Holzman, M., Rivas, R., Carmona, F. \& Niclos, R, "A method for soil moisture probes calibration and validation of satellite estimates," MethodsX, vol. 4, pp. 243-249, 2017.

[8] Ekawita, R., Nawir, H., Suprijadi, \& Khairurrijal, "Determination of young's moduli of clays using image processing technique and stressstrain calculation," ARPN Journal of Engineering \& Applied Science, vol. 10(18), pp. 8283-8289, 2015.

[9] Liu, J., Suo, X.M., Zhou, S.S., Meng, S.Q., Chen, S.S. \& Mu, H.P, "Electrical capacitance tomography measurement of the migration of ice frontal surface in freezing soil," Measurement Science Review, vol. 16(6), pp. 280-286, 2016

[10] Mohan, R. R., Paul, B., Mridula, S. \& Mohanan, P, "Measurement of soil moisture content at microwave frequencies," Procedia Computer Science, vol. 46, pp. 1238 - 1245, 2014.

[11] Yeow, Y.K., Abbas, Z. \& Kaida Khalid, "Application of microwave moisture sensor for determination of oil palm fruit ripeness," Measurement Science Review, vol. 10(1), pp. 7-14, 2010.

[12] Pereira, M. D., Postolache, O. \& Girão. P.S, "A smart measurement and stimulation system to analyze and promote non-nutritive sucking of premature babies," Measurement Science Review, vol. 11(6), pp. 173-180, 2011.

[13] Haddab, S. \& M.Laghrouche, "Microcontroller -based system for electrogastrography monitoring through wireless transmission," Measurement Science Review, vol. 9(5), pp. 122-126, 2009.

[14] Zhou, Y., Srinivasan, R. \& Lakshminarayanan, S, "Critical evaluation of image processing approaches for real time crystal size measurement," Computer and Chemical Engineering, vol. 33, pp. 1022-103, 2008.

[15] Bono, R. W., Dillon, M. J., Gatzwiller, K. B., Brown, D. L., New Developments in Multi-channel Test Systems.

[16] Operator's Manual, "10HS Soil Moisture Sensor. Decagon Devices," Inc. www.decagon.com, 2008.
About author (s) :

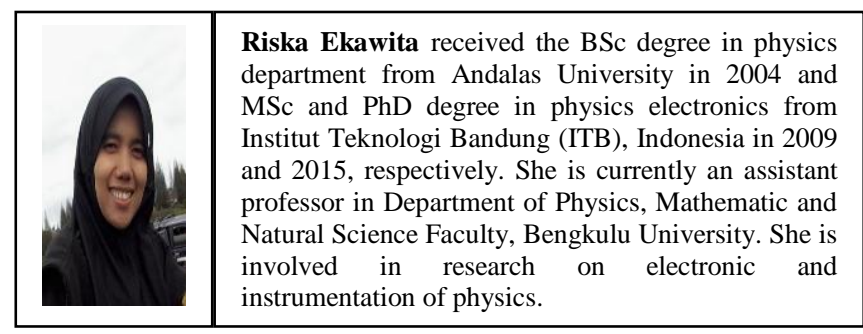

\begin{tabular}{|l|l|} 
Zul Bahrum Caniago was born in Padang, \\
November 25, 1957. He obtained BSc degree in \\
Physics Education at State University of Yogyakarta \\
(UNY) in 1984. His MSc degree in Physics \\
Instrumentation was achieved at Institut Teknologi \\
Bandung (ITB) in 1991. He got his PhD degree in \\
Environment Science from Sriwijaya University in \\
2014. He is currently interested in the development
\end{tabular}

\begin{tabular}{|l|l|}
\hline & $\begin{array}{l}\text { Supanjani passed his BSc degree in agronomy at } \\
\text { Bogor Agriculture University in 1986. His MSc } \\
\text { degree in Plant Science was achieved at Massey } \\
\text { University, New Zealand in 1991. He got his PhD } \\
\text { degree in Plant Science from McGill University, } \\
\text { Canada. He is currently interested in the } \\
\text { development of cultivation technologies of guava } \\
\text { and date palm, and the ecology of oil palm. }\end{array}$ \\
\hline
\end{tabular}

\begin{tabular}{|l|l|}
\hline & $\begin{array}{l}\text { Abimanyu Dipo Nusantara got his BSc in soil } \\
\text { science from Jember University in 1981, MSc degree } \\
\text { in soil science from Gajah Mada University in 1986 } \\
\text { and PhD in forest science from Bogor Agriculture } \\
\text { University in 2011. He is currently interested in the } \\
\text { development of soil microorganism consortium for } \\
\text { remedying problem of soil. }\end{array}$ \\
\hline
\end{tabular}

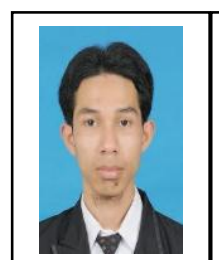

Muhammad Sainal Abidin graduated from BSc and MSc degree in physics department of Halu Oleo University in 2010 and Institut Teknologi Bandung in 2015. He is currently as a lecturer of STIKES Mandala Waluya Kendari in electromedical engineering program. $\mathrm{He}$ is involved in research on electronic and instrumentation.

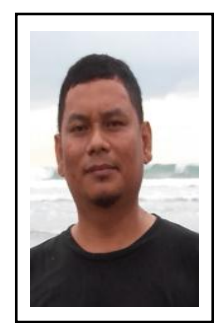

Yazid Ismi Intara received the $\mathrm{BSc}$ degree in agronomy department from Mulawarman University in 1999 and $\mathrm{MSc}$ and $\mathrm{PhD}$ degree in agriculture engineering from Bogor Agriculture University, Indonesia in 2005 and 2012, respectively. He is currently an assistant professor in Faculty of Agriculture in Mulawarman University. $\mathrm{He}$ is currently interested in the agriculture and irrigation engineering. 